\title{
Role of manganese on the structure, crystallization and sintering of non-stoichiometric lithium disilicate glasses
}

\author{
Anuraag Gaddam, ${ }^{a}$ Hugo R. Fernandes, ${ }^{a}$ Dilshat U. Tulyaganov, ${ }^{\text {ab }}$ Maria J. Pascual $^{\mathrm{c}}$ \\ and José M. F. Ferreira*a
}

The structural role of $\mathrm{Mn}$ was investigated in a relatively simple non-stoichiometric lithium disilicate $\left(\mathrm{Li}_{2} \mathrm{Si}_{2} \mathrm{O}_{5}\right)$ based glass composition. Glasses were prepared by partially replacing $\mathrm{SiO}_{2}$ by $\mathrm{MnO}_{2}$ from the base glass belonging to the system $\mathrm{Li}_{2} \mathrm{O} \quad \mathrm{K}_{2} \mathrm{O} \quad \mathrm{Al}_{2} \mathrm{O}_{3} \quad \mathrm{SiO}_{2}$. An overall depolymerization of the glass network was observed according to magic angle spinning nuclear magnetic resonance (MAS-NMR) and Fourier transform infrared (FTIR) spectroscopic studies, suggesting a network modifier role for $\mathrm{Mn}$. However, thermal analysis, phase segregation and nucleation in the glasses suggested that $\mathrm{Mn}$ might also act as network former. Moreover, calculated crystal field parameters from UV-Visible spectroscopy, showing high ligand field strength $\left(\Delta_{\circ}\right)$ and Racah inter electronic repulsion $(B)$ indicate the possible existence of $\mathrm{Mn}$ as individual molecular entities in the interstitials of the glass network. This paper discusses the implications of this structural role of $\mathrm{Mn}$ on the crystallization of bulk glasses and on the sintering behaviour and crystallization of glass powder compacts.

Received 4th November 2013 Accepted 28th February 2014

DOI: 10.1039/c3ra46393a

www.rsc.org/advances activator in many crystals and glasses and the $\mathrm{Mn}^{2+}$ ion exhibits broadband emission characteristics. ${ }^{4,5}$ In a molten glass, the $\mathrm{Mn}$ cations distribute into couple states such as $\mathrm{Mn}^{2+}-\mathrm{Mn}^{3+}$. According to Schreiber, ${ }^{6}$ the change in redox depends on glass composition, melting temperature, atmosphere, concentration of redox couples and the presence of other redox couples. At a given melting condition, the redox couple shifts towards the oxidized state when modifier ions or glass basicity are increased. $^{7}$

$\mathrm{Mn}$ in glasses may be expected to be in the form of $\mathrm{MnO}_{4}{ }^{-}$ and $\mathrm{MnO}_{4}{ }^{2-}$ anions, and in the form of $\mathrm{Mn}^{2+}, \mathrm{Mn}^{3+}$ and $\mathrm{Mn}^{4+}$ cations, or a mixture of these. ${ }^{8}$ It has been demonstrated that all Mn oxides when heated to $1000{ }^{\circ} \mathrm{C}$ and higher are transformed into $\mathrm{Mn}$ orthomanganate $\left(\mathrm{Mn}_{2}{ }^{2+} \mathrm{Mn}^{4+} \mathrm{O}_{4}\right) \cdot{ }^{9,10}$ Manganese ions exist in different valence states occupying tetrahedral or octahedral sites in a glass network. For example, $\mathrm{Mn}^{3+}$ ions in borate glasses exist only in octahedral coordination, whereas in silicate and germanate glasses are in both tetrahedral and octahedral environments. ${ }^{11}$ Tetrahedral and octahedral $\mathrm{Mn}^{2+}$ ions exhibit luminescence emission in the green and red regions for various glasses, respectively. ${ }^{12}{ }^{14}$ Therefore, $\mathrm{Mn}^{2+}$, having a coordination number of six in silicate glasses, plays a modifying cation role, but $\mathrm{Mn}^{4+}$, forming coordinate polyhedra $\left[\mathrm{MnO}_{4}\right]^{4-}$, may participate in the formation of a glass network together with $\mathrm{Si}^{4+}$.

The content and valence states of $\mathrm{Mn}$ in various environments in the glasses are dependent on quantitative properties of modifiers and glass formers, size of the ions in the glass structure, their field strength, mobility of the modifier cation, etc. ${ }^{15,16}$ 
Several interesting studies are available regarding the use of Mn as a colouring agent for glass matrices (e.g. ref. 17-22), as well as on the environment of $\mathrm{Mn}$ ion in various inorganic glass systems (e.g. ref. 23-32). However, most of these works report studies in borate, phosphate or other glass systems and few studies have been carried on silicate based glasses. The present study aims towards investigating the role of manganese on the glass structure of a relatively simple non-stoichiometric lithium disilicate based glass composition in the glass forming region of $\mathrm{Li}_{2} \mathrm{O}-\mathrm{K}_{2} \mathrm{O}-\mathrm{Al}_{2} \mathrm{O}_{3}-\mathrm{SiO}_{2}$ with $\mathrm{SiO}_{2} / \mathrm{Li}_{2} \mathrm{O}$ molar ratio of 3.12. Based on the established role of the $\mathrm{Mn}$ in the glass structure this paper discusses (1) crystallization in bulk glasses and (2) sintering behaviour and crystallization in glass powder compacts.

\section{Experimental procedure}

\subsection{Glass preparation}

Four experimental glass compositions were prepared using a general formula (mol\%): $23 \mathrm{Li}_{2} \mathrm{O}-2.64 \mathrm{~K}_{2} \mathrm{O}-2.64 \mathrm{Al}_{2} \mathrm{O}_{3}-(71.72 \quad x)$ $\mathrm{SiO}_{2}-x \mathrm{MnO}_{2}$, with $x$ varying from 0 to 2 (Table 1). Accordingly, these glasses were designated as GMn0.0 $(x=0.0)$, GMn0.5 $(x=0.5)$, GMn1.0 $(x=1.0)$ and GMn2.0 $(x=2.0)$. In all compositions, molar concentrations of $\mathrm{Li}_{2} \mathrm{O}, \mathrm{K}_{2} \mathrm{O}$ and $\mathrm{Al}_{2} \mathrm{O}_{3}$ were kept constant, while $\mathrm{SiO}_{2}$ has been partially replaced by $\mathrm{MnO}_{2}$.

Powders of technical grade $\mathrm{SiO}_{2}$ (purity $>99 \%$ ) and reagent grade $\mathrm{Li}_{2} \mathrm{CO}_{3}$ (purity $>99 \%$ ), $\mathrm{K}_{2} \mathrm{CO}_{3}$ (purity $>99 \%$ ), $\mathrm{Al}_{2} \mathrm{O}_{3}$ (purity $>99 \%$ ) and $\mathrm{MnO}_{2}$ (purity > 99\%) were used as precursors. To give batch compositions of $100 \mathrm{~g}$, these powders were homogenously mixed by ball milling, and then calcined at $800{ }^{\circ} \mathrm{C}$ for $1 \mathrm{~h}$. Pt crucibles were used to melt the compositions at $1550{ }^{\circ} \mathrm{C}$ for $1 \mathrm{~h}$ in air. Bulk (monolithic) glasses were prepared by pouring the glass melt on a bronze mould and immediately annealing at $450{ }^{\circ} \mathrm{C}$ for $1 \mathrm{~h}$. To prepare glass powder, glass frits were obtained by quenching the glass melts in cold water. The frits were dried and milled in a high speed agate mill in order to obtain a particle size between 5 and $10 \mu \mathrm{m}$ as determined by the particle size analyser (Coulter LS 230, Fraunhofer optical model, Amherst, MA). Rectangular bars having dimensions $4 \mathrm{~mm} \times 5$ $\mathrm{mm} \times 50 \mathrm{~mm}$ were prepared by uniaxial pressing of glass powders with a pressure of $80 \mathrm{MPa}$ for 10 seconds.

\subsection{Heat treatment schedule}

Bulk glasses from all the four compositions were cut into required size and heat treated at a heating rate of $2 \mathrm{~K} \mathrm{~min}^{-1}$ in air up to temperatures in the range of $650-900{ }^{\circ} \mathrm{C}$ with intervals of $50{ }^{\circ} \mathrm{C}$ and kept for $1 \mathrm{~h}$ at the set temperatures. Using the same

Table 1 Compositions of the glass in mol\%

\begin{tabular}{lrrrr}
\hline & GMn0.0 & GMn0.5 & GMn1.0 & GMn2.0 \\
\hline $\mathrm{Li}_{2} \mathrm{O}$ & 23.00 & 23.00 & 23.00 & 23.00 \\
$\mathrm{~K}_{2} \mathrm{O}$ & 2.64 & 2.64 & 2.64 & 2.64 \\
$\mathrm{Al}_{2} \mathrm{O}_{3}$ & 2.64 & 2.64 & 2.64 & 2.64 \\
$\mathrm{SiO}_{2}$ & 71.72 & 71.22 & 70.72 & 69.72 \\
$\mathrm{MnO}_{2}$ & 0.00 & 0.50 & 1.00 & 2.00 \\
$\mathrm{SiO}_{2} / \mathrm{Li}_{2} \mathrm{O}$ & 3.12 & 3.10 & 3.07 & 3.03
\end{tabular}

heating rate $\left(2 \mathrm{~K} \mathrm{~min}^{-1}\right)$, glass powder compacts were sintered at 800,850 and $900{ }^{\circ} \mathrm{C}$ for $1 \mathrm{~h}$ in air.

\subsection{Characterization of the samples}

Differential thermal analysis (DTA, Setaram Labsys, Setaram Instrumentation, Caluire, France) was carried out on all glass compositions obtained by crushing the glass frits having particle sizes between 5 and $10 \mu \mathrm{m}(\sim 6 \mu \mathrm{m}$, particle size analyser). DTA experiments were carried out in air from ambient temperature to $1000{ }^{\circ} \mathrm{C}$ at a heating rate of $20 \mathrm{~K} \mathrm{~min}^{-1}$ using $\sim 30 \mathrm{mg}$ of sample in an alumina crucible, with $\alpha$-alumina powder as reference material. For GMn0.0 and GMn2.0, a heating rate of $5 \mathrm{~K} \mathrm{~min}^{-1}$ was also performed to compare with hot-stage microscopy (HSM) results.

Optical transmission spectra were obtained for all bulk glasses using polished samples (on both parallel sides) with thickness of $\sim 0.9 \mathrm{~mm}$. The spectra were recorded over a range 200-800 $\mathrm{nm}$ wavelength using UV-VIS-NIR spectrophotometer (UV-3100, Shimadzu, Japan). Infrared transmittance spectra of glass powders prepared by crushing the bulk annealed glasses were obtained using Fourier Transform Infrared Spectrometer (FTIR, model Mattson Galaxy S-7000, USA) in the range of 300$1400 \mathrm{~cm}^{-1}$. Samples for FTIR were prepared by mixing $1 / 150$ (by weight) portion of the sample with $\mathrm{KBr}$ and hand pressed to obtain pellets. ${ }^{29} \mathrm{Si}$ MAS-NMR spectra was recorded for glass powders prepared from frit glass on a Bruker ASX 400 spectrometer operating at a Larmor frequency of $79.52 \mathrm{MHz}$ with $9.4 \mathrm{~T}$ magnetic field $\left(B_{\mathrm{o}}\right)$ using a $7 \mathrm{~mm}$ probe rotating at $5 \mathrm{kHz}$. A $5 \mu$ s length radio-frequency excitation pulse equivalent to $90^{\circ}$ flip angle with $60 \mathrm{~s}$ delay time was used. Kaolinite was used as chemical shift reference. ${ }^{27} \mathrm{Al}$ MAS-NMR spectra were recorded on a Bruker ASX 400 spectrometer operating at a Larmor frequency of $104.28 \mathrm{MHz}$ with $9.4 \mathrm{~T}$ magnetic field $\left(B_{\mathrm{o}}\right)$ using a $4 \mathrm{~mm}$ probe rotating at $15 \mathrm{kHz}$. A $0.78 \mu$ s radio-frequency pulse length equivalent to $10^{\circ}$ flip angle with $1 \mathrm{~s}$ delay time was used. $\mathrm{Al}\left(\mathrm{NO}_{3}\right)_{3}$ was used as the chemical shift reference.

Microstructures of the samples were recorded using reflected light optical microscope (Jenaphot 2000, Zeiss, Germany) and scanning electron microscope (SEM, SU-70, Hitachi, Japan). For microstructural observation, samples were polished and etched using 2 vol\% hydrofluoric acid for $60 \mathrm{~s}$. Crystalline phase content in the samples was determined by X-ray diffraction (XRD, Rigaku Geigerflex D/Mac, C Series, Japan) using $\mathrm{Cu} \mathrm{K \alpha}$ radiation with $2 \theta$ varying from $10-60^{\circ}$ steps of $0.02 \mathrm{~s}^{-1}$.

A side-view hot-stage microscope (HSM, Leitz Wetzlar, Germany) equipped with a Pixera video camera and image analysis system was used to investigate the sintering behaviour of glass powder compacts. The cylindrical shaped samples from glass powder compacts with height and diameter of $\sim 3 \mathrm{~mm}$ were prepared by cold-pressing the glass powders. The cylindrical samples were placed on a $10 \mathrm{~mm} \times 15 \mathrm{~mm} \times 1 \mathrm{~mm}$ alumina $\left(>99.5 \mathrm{wt} \% \mathrm{Al}_{2} \mathrm{O}_{3}\right)$ support and the measurements were conducted in air with a heating rate $(\beta)$ of $5 \mathrm{~K} \mathrm{~min}^{-1}$. The temperature was measured with a chromel-alumel thermocouple contacted under the alumina support. The temperatures corresponding to the characteristic viscosity points (first shrinkage 
( $\left.T_{\mathrm{FS}}\right)$, maximum shrinkage ( $\left.T_{\mathrm{MS}}\right)$, softening $\left(T_{\mathrm{D}}\right)$, half ball $\left(T_{\mathrm{HB}}\right)$ and flow $\left(T_{\mathrm{F}}\right)$ ) were obtained from the graphs and photomicrographs taken during the hot-stage microscopy experiment.

Apparent densities of the all the samples (bulk glasses, bulk glass-ceramics and sintered glass powder compacts) were measured using Archimedes principle by immersion in ethylene glycol. 3-point bending strength of the sintered glass powder compacts were performed using universal testing machine (Shimadzu Autograph AG 25 TA).

\section{Results}

With increasing the $\mathrm{MnO}_{2}$ content in the experimental glass compositions, the melts demonstrated severe bubbling at temperatures close to $1550{ }^{\circ} \mathrm{C}$. However, the bubbles were of relatively large sizes and were confined to the top surface of the melt. Therefore the cast glasses obtained were transparent and bubble free.

\subsection{Optical study of bulk glasses}

Glasses GMn0.0 and GMn0.5 were colourless and light pink respectively, whilst GMn1.0 and GMn2.0 showed a very strong colouring to purple. Fig. 1 shows the UV-Visible transmittance spectra of the experimental glasses. Glass with no Mn addition (GMn0.0) did not show any absorption bands in the investigated region, whereas $\mathrm{Mn}$ doped glasses showed broad absorptions bands with magnitude proportional to Mn content. There are two absorption bands at $\sim 474 \mathrm{~nm}$ and $631 \mathrm{~nm}$ in glass GMn0.5. Glass GMn1.0 featured three absorption bands at $489 \mathrm{~nm}, 581 \mathrm{~nm}$ and $638 \mathrm{~nm}$. In the glass GMn2.0, the absorption bands are obtained at $478 \mathrm{~nm}$ and $631 \mathrm{~nm}$. The purple colour in the Mn doped glasses is usually attributed to $\mathrm{Mn}^{3+}$ ions which exhibit absorption at $\sim 480 \mathrm{~nm} .{ }^{6,33}{ }^{36}$ With $\mathrm{Mn}$ in 2+ oxidation state the absorption bands usually are centred near ultraviolet regions. ${ }^{35,36}$ Therefore, based on the UV-Visible spectra of experimental glasses suggesting the strongest absorption bands at $\sim 470 \mathrm{~nm}$ it is reasonable to conclude that Mn ions mostly exist in 3+ oxidation state. This assumption will be further discussed in the subsequent sections.

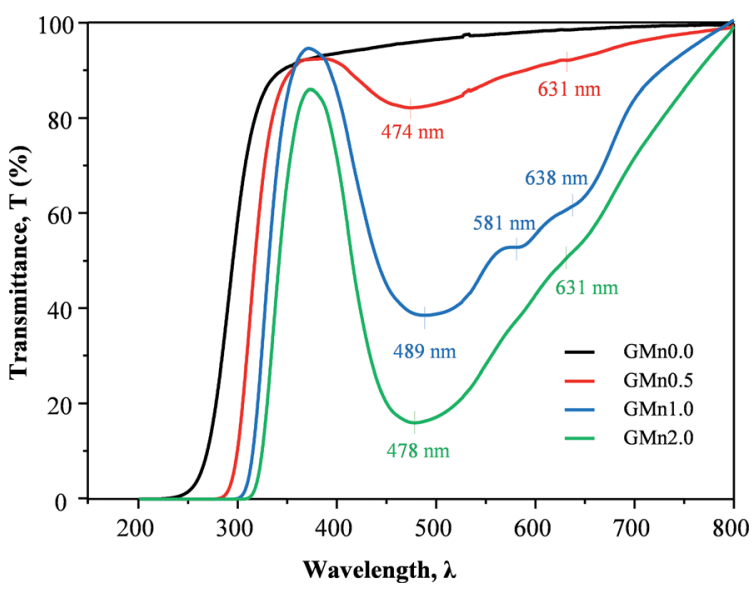

Fig. 1 UV-Visible transmittance spectra of experimental glasses.
From Fig. 1, the glass GMn1.0 was selected and the absorption bands were identified from their position in the UV-Visible spectra using Tanabe-Sugano diagrams. Additionally, the octahedral ligand field splitting parameter $\Delta_{\mathrm{o}}$ and inter-electronic repulsion Racah parameter $B$ values were determined. Based on the ligand field strength consideration and $3 \mathrm{~d}^{4}$ electronic configuration of $\mathrm{Mn}^{3+}$, the electrons can exist in high spin or low spin states for low and high ligand field strengths, respectively. ${ }^{37}$ Subsequently, the ground state configurations are ${ }^{5} E_{\mathrm{g}}$ and ${ }^{3} T_{1 \mathrm{~g}}$ for low and high field ligand field strength, respectively. Based on calculations from the Tanabe-Sugano diagrams, the ground state was identified as ${ }^{3} T_{1 g}$. Also the absorption bands in the regions $\sim 480 \mathrm{~nm}, \sim 580 \mathrm{~nm}$ and $\sim 630$ $\mathrm{nm}$ correspond to the transitions ${ }^{3} T_{1 \mathrm{~g}} \rightarrow{ }^{5} E_{\mathrm{g}},{ }^{3} T_{1 \mathrm{~g}} \rightarrow{ }^{1} T_{2 \mathrm{~g}}$ and ${ }^{3} T_{1 \mathrm{~g}} \rightarrow{ }^{1} E_{\mathrm{g}}$, respectively. Further, due to Jahn-Teller distortion, the ground state further splits. ${ }^{35}$ For GMn1.0, the ligand field splitting parameter was calculated to be $\Delta_{\mathrm{o}}=53494 \mathrm{~cm}^{-1}$ and Racah parameter $B=1392 \mathrm{~cm}^{-1}$.

From the Beer-Lambert law, the linear attenuation coefficient $\alpha$ can be calculated using an approximate equation given by,

$$
\alpha=\frac{1}{t} \ln T
$$

where, $t$ is the thickness of the glass sample and $T$ is measured transmittance. From the transmittance spectra, the optical band gap energy can be calculated using Tauc relationship given by the equation,

$$
\alpha h \nu=A\left(\begin{array}{ll}
h \nu & E_{\mathrm{g}}
\end{array}\right)^{n}
$$

where, $\alpha$ is linear attenuation coefficient, $h$ is Planck's constant, $\nu$ is the frequency of the photon, $A$ is a constant related to the extent of band tailing, $E_{\mathrm{g}}$ is the band gap energy and the exponent $n$ depends on the nature of the material. For direct band gap $n=1 / 2$, and for indirect band gap $n=2$. A Tauc plot is drawn with energy of the photon $(h \nu)$ on abscissa and $(\alpha h \nu)^{1 / n}$ on ordinate. An extrapolation of the linear portion of the curve onto the abscissa would yield optical band gap energy; because, when $(\alpha h \nu)^{1 / n}=0$, then $E_{\mathrm{g}}=h \nu$. In the present work, both direct and indirect band gaps were calculated, i.e. for both $n=1 / 2$ and 2. Fig. 2a and $\mathrm{b}$ shows the Tauc plots for $n=1 / 2$ and $n=2$, respectively. In both cases, it can be noticed that there is red shift in the optical band gap (i.e. decreasing $E_{\mathrm{g}}$ ) with increasing Mn content.

\subsection{FTIR}

The FTIR transmittance spectra of the experimental glasses are presented in Fig. 3. Due to the amorphous nature of the glasses and wide distribution of $Q^{n}$ units, there is a lack of sharpness in the absorption bands. All experimental glass compositions showed four absorption bands; of which one broad peak is centred at $\sim 1050 \mathrm{~cm}^{-1}$. Two sharper peaks centred at $\sim 470 \mathrm{~cm}^{-1}$ and $\sim 780 \mathrm{~cm}^{-1}$. With Mn content increasing, the peak centred at $\sim 1050 \mathrm{~cm}^{-1}$ broadens more. The assignment of these bands is as follows: ${ }^{38}$ 

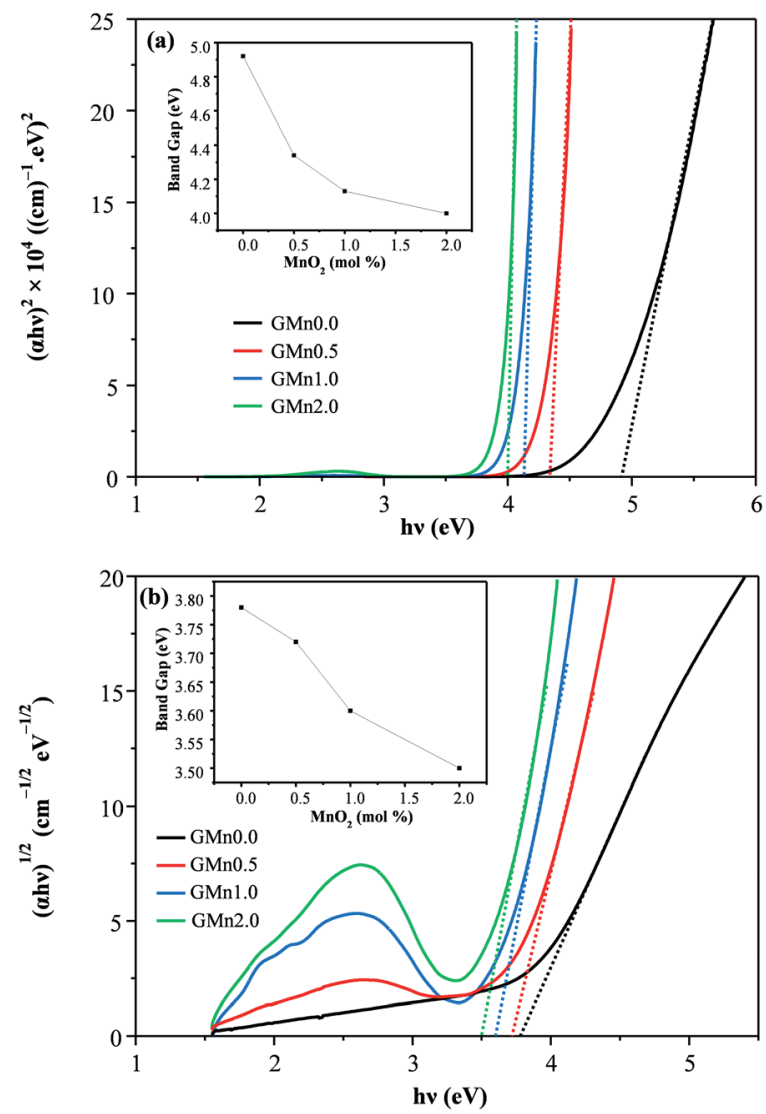

Fig. 2 Tauc plots for (a) direct band gap, $n$ 1/2; and (b) indirect band gap, $n \quad 2$.

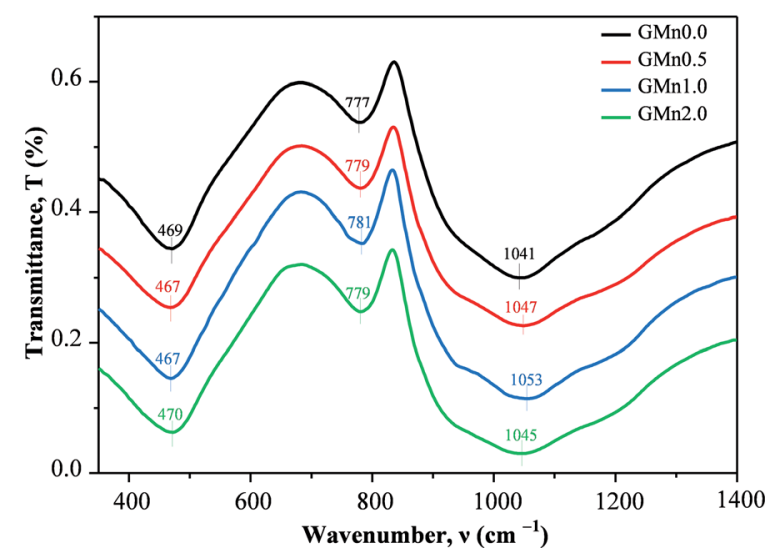

Fig. 3 FTIR of annealed bulk glasses.

1. The low frequency band at $\sim 470 \mathrm{~cm}^{-1}$ is attributed to transverse-optical $\left(T \mathrm{O}_{1}\right)$ mode $\rho(\mathrm{Si}-\mathrm{O}-\mathrm{Si})$ correspond to rocking motions of oxygen atoms. It could also be attributed to the symmetric stretching vibrations of $\mathrm{LiO}_{4}$ tetrahedra.

2 . The band near $\sim 780 \mathrm{~cm}^{-1}$ is characteristic of transverseoptical $\left(\mathrm{TO}_{2}\right)$ mode $\nu_{\mathrm{s}}(\mathrm{Si}-\mathrm{O}-\mathrm{Si})$ caused by symmetric stretching of oxygen atoms.

3. The broad band at $\sim 1050 \mathrm{~cm}^{-1}$ is due transverse-optical $\left(\mathrm{TO}_{3}\right)$ mode $\nu_{\text {as }}(\mathrm{Si}-\mathrm{O}-\mathrm{Si})$ appear as a result of antisymmetric stretching of the oxygen atoms. The shoulder at high frequency side of this band is also a characteristic of this mode.

\subsection{MAS-NMR}

The ${ }^{29} \mathrm{Si}$ MAS-NMR spectra for experimental glasses GMn0.5, GMn1.0 and GMn2.0 are shown in Fig. 4a. It is to be noted that due to the amorphous nature of the glasses, they gave a broad peak indicating the wide distribution of $Q^{n}$ units. The spectra of GMn0.5, GMn1.0 and GMn2.0 glasses show that the broad peak is centred at $95.3 \mathrm{ppm}, \quad 93.2 \mathrm{ppm}$ and $92.8 \mathrm{ppm}$ respectively suggesting a depolymerisation trend of the glass network at 0.5 to $2 \mathrm{~mol} \% \mathrm{MnO}_{2}$ additions. At the same time broadening of the main peaks due to extended distribution of the $Q^{n}$ units can be observed. According to De Jong et al. ${ }^{39}$ for various $Q^{n}$ units the mean chemical shifts were as follows: $107 \mathrm{ppm}\left(Q^{4}\right), \quad 92 \mathrm{ppm}$ $\left(Q^{3}\right), \quad 82 \mathrm{ppm}\left(Q^{2}\right)$ and $69 \mathrm{ppm}\left(Q^{1}\right)$. Therefore, the centring of the peaks between 92 and $96 \mathrm{ppm}$ in the experimental glasses evidenced that $Q^{3}$ is the dominant species. However, the shoulders centred at about $104.5 \mathrm{ppm}$ in glass GMn0.5 suggest presence of $Q^{4}$ units in the experimental glasses.

${ }^{27} \mathrm{Al}$ MAS-NMR spectra are shown in Fig. $4 \mathrm{~b}$. It can be noticed that for all the experimental glass compositions the chemical shift peaks are centred at $\sim 52 \mathrm{ppm}$. This is a characteristic
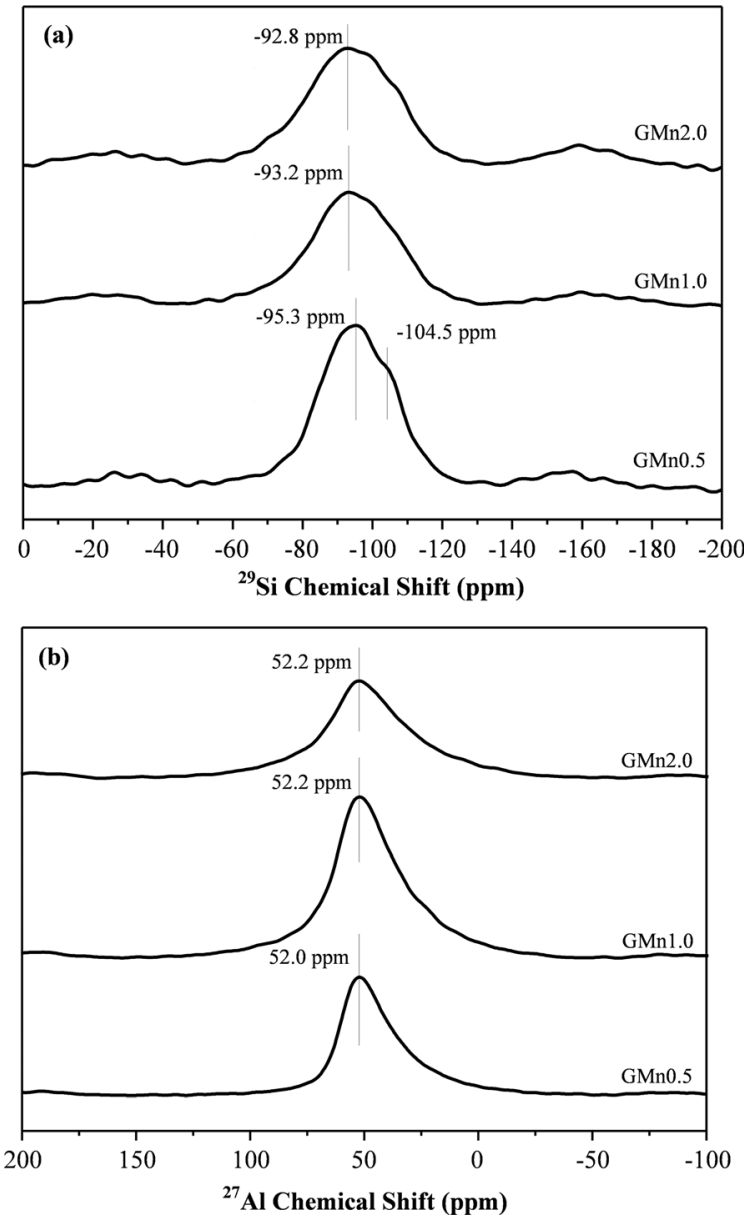

Fig. 4 (a) ${ }^{29} \mathrm{Si}$ MAS-NMR and (b) ${ }^{27}$ Al MAS-NMR spectra of experimental glasses. 


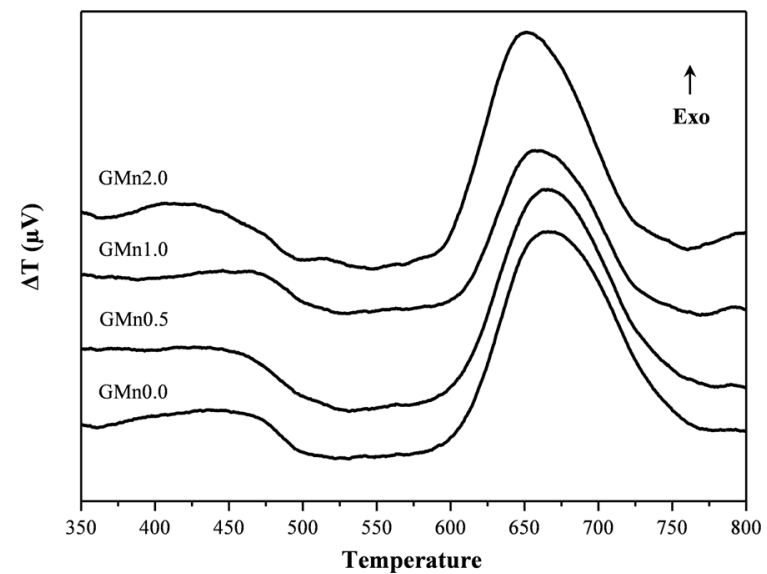

Fig. 5 DTA of experimental glasses at heating rate of $20 \mathrm{~K} \mathrm{~min}^{1}$.

feature for aluminium existing in a glass network with tetrahedral coordination. ${ }^{4042}$

\subsection{Thermal and other properties of bulk glasses}

DTA thermographs for the glass powders are shown in Fig. 5. The properties of the experimental glasses, including glass transition temperature $\left(T_{\mathrm{g}}\right)$, peak crystallization temperature $\left(T_{\mathrm{p}}\right)$, molar volumes $\left(V_{\mathrm{m}}\right)$, density and optical basicity values of experimental glasses and other thermal parameters are presented in Table 2. The Hrubÿ parameter of glass stability $\left(K_{\mathrm{H}}\right)$ was calculated by the equation, ${ }^{\mathbf{4 3}}$

$$
K_{\mathrm{H}}=\frac{\left(\begin{array}{ll}
T_{\mathrm{p}} & T_{\mathrm{g}}
\end{array}\right)}{\left(\begin{array}{ll}
T_{\mathrm{m}} & T_{\mathrm{g}}
\end{array}\right)}
$$

The $K_{\mathrm{H}}$ values gradual decrease with Mn addition, while the reduced glass-transition temperature $\left(T_{\mathrm{gr}}\right)$ given by $T_{\mathrm{g}} / T_{\mathrm{m}}$ shows an apparent opposite trend. The calculation of molar volumes $\left(V_{\mathrm{m}}\right)$ given by $M / \rho$ (where, $M$ is molar mass and $\rho$ is density of the glasses) was based on the optical study, assuming that majority of Mn exists in 3+ oxidation state. The optical basicity of glasses was calculated using the general formula: ${ }^{44}$

$$
\Lambda_{\mathrm{cal}}=X_{\mathrm{A}} \frac{1}{\gamma_{\mathrm{A}}}+X_{\mathrm{B}} \frac{1}{\gamma_{\mathrm{B}}}+\ldots
$$

where $\Lambda_{\text {cal }}$ is the calculated optical basicity, $\gamma_{\mathrm{A}}$ and $\gamma_{\mathrm{B}}$ are basicity moderating parameters, and $X_{\mathrm{A}}$ and $X_{\mathrm{B}}$ are mole fractions of oxides A and B, respectively.

\begin{tabular}{|c|c|c|c|c|}
\hline & GMn0.0 & GMn0.5 & GMn1.0 & GMn2.0 \\
\hline$T_{\mathrm{g}} \pm 2\left({ }^{\circ} \mathrm{C}\right)$ & 460 & 458 & 467 & 465 \\
\hline$T_{\mathrm{p}} \pm 2\left({ }^{\circ} \mathrm{C}\right)$ & 665 & 665 & 657 & 651 \\
\hline$K_{\mathrm{H}}$ & 0.41 & 0.40 & 0.40 & 0.39 \\
\hline$T_{\mathrm{gr}}$ & 0.58 & 0.58 & 0.59 & 0.59 \\
\hline Density $\left(\mathrm{g} \mathrm{cm}^{3}\right)$ & $2.36 \pm 0.01$ & $2.38 \pm 0.01$ & $2.39 \pm 0.01$ & $2.39 \pm 0.01$ \\
\hline $\begin{array}{l}\text { Molar volume, } \\
V_{\mathrm{m}}\left(\mathrm{cm}^{3} \mathrm{~mol}^{1}\right)\end{array}$ & 23.37 & 23.25 & 23.28 & 23.46 \\
\hline Calculated optical & 0.5279 & 0.5282 & 0.5285 & 0.5291 \\
\hline
\end{tabular}

Table 2 Properties of the experimental glasses

basicity, $\Lambda_{\text {cal }}$

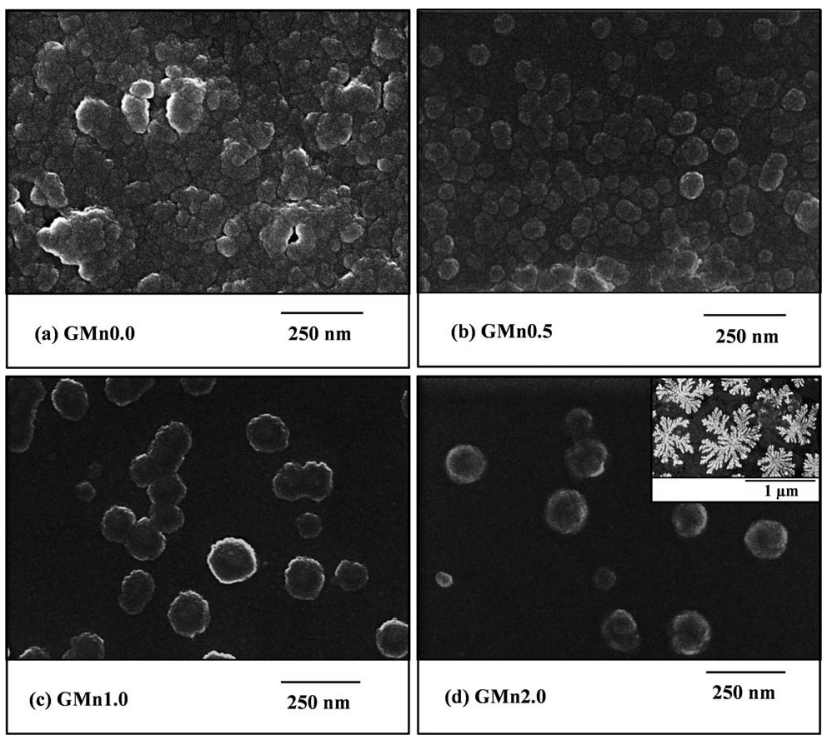

Fig. 6 SEM images of bulk annealed glass revealing phase segregation.

\subsection{Microstructural and phase analysis of bulk glasses and glass-ceramics}

Fig. 6 presents the microstructures of the annealed bulk glasses showing the presence of metastable glass immiscibility regions. With increasing the $\mathrm{MnO}_{2}$ content two main trends can be inferred from the micrographs: (a) the size of segregated droplets increases; (b) the population density of the droplets decreases. Additionally, in the composition GMn2.0, the microstructure reveals a growth of dendritic type crystals (Fig. 6, insert).

Fig. 7a-d presents optical micrographs of glass samples GMn0.0 and GMn0.5 heat treated at $700{ }^{\circ} \mathrm{C}$, (Fig. 7a and b) and at $800{ }^{\circ} \mathrm{C}$ (Fig. 7c and d). At $700{ }^{\circ} \mathrm{C}$, the GMn0.0 sample reveals the formation of both bulk crystalline clusters and surface dendritic crystallization. The Mn addition (GMn0.5) seemingly decreased the population density of bulk crystalline clusters while concomitantly increased the thickness of the surface layer (Fig. 7b), variations that can be associated with a favoured tendency towards surface crystallization. With increasing the heat treatment temperature to $800{ }^{\circ} \mathrm{C}$, the spherulites and dendrites merged resulting in the formation of fully crystallised structures (Fig. 7c and d).

Fig. 8 compares the X-ray diffractograms of experimental bulk glasses heat treated at various temperatures. Key points to be noticed from these diffractograms are as follows:

1. Lithium metasilicate and lithium disilicate start to form at $700{ }^{\circ} \mathrm{C}$ in all glass compositions and continue to grow upon further increasing the heat treatment temperature.

2. The formation of minor amounts of quartz took place at $900{ }^{\circ} \mathrm{C}$ for glasses GMn0.0 and GMn0.5, but at a lower temperature $\left(800{ }^{\circ} \mathrm{C}\right)$ for glasses GMn1.0 and GMn2.0.

Non-heat treated annealed bulk glass GMn 2.0 shows a very low intensity single peak at $2 \theta=31.3^{\circ}$, almost coincident with a peak of LS, but which could not be surely assigned to any phase. 


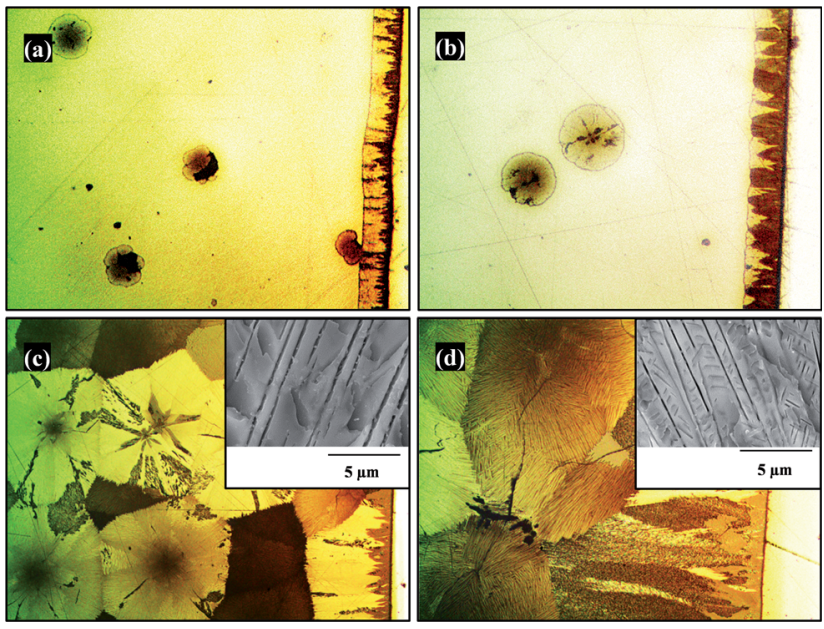

Fig. 7 Microstructures of bulk glass ceramics of samples (a) GMn0.0 and (b) GMn0.5 heat treated at $700{ }^{\circ} \mathrm{C}$ for $1 \mathrm{~h}$; and (c) GMn0.0 and (d) GMn0.5 heat treated at $800^{\circ} \mathrm{C}$ for $1 \mathrm{~h}$; pictures were taken by optical microscope with a magnification of $\times 50$ and the surface layer is on the right side of the image. The inserts in (c) and (d) are the corresponding higher magnification images.

\subsection{Microstructural and phase analysis of sintered glass powder compacts}

Fig. 9 shows relatively low magnification SEM images of glass-powder compacts made for three compositions (GMn0.0, GMn1.0, and GMn2.0 - lines) sintered at different temperatures $\left(800,850\right.$ and $900{ }^{\circ} \mathrm{C}-$ columns $)$, to shed light on the porosity; while Fig. 10 presents more detailed microstructural features of the same samples sintered at 800 and $900{ }^{\circ} \mathrm{C}$.

$\mathrm{X}$-ray diffractograms of samples sintered in the range from $800-900{ }^{\circ} \mathrm{C}$ are presented in the Fig. 11 . At $800{ }^{\circ} \mathrm{C}$, LS emerged as major crystalline phase in GMn0.0 together with minor amounts of LD and quartz, while LD was already formed at this temperature for all Mn containing samples, becoming even the major phase for the higher added amounts of $\mathrm{Mn}$. Therefore, $\mathrm{Mn}$ addition favours the formation of LD over LS.

\subsection{Sintering behaviour and mechanical strength of glass powder compacts}

Fig. 12 shows the sintering behaviour of the glass powder compacts of GMn0.0 and GMn2.0 under a constant heating rate of $5 \mathrm{~K} \mathrm{~min}^{-1}$ from room temperature (RT) to $1000{ }^{\circ} \mathrm{C}$. DTA curves are also presented along with the HSM results. Characteristic points of sintering and crystallization are presented in Table 3.

The effects of Mn content on density and flexural strengths variations with sintering temperature are presented in Fig. 13. Increasing up to maximum values followed decreasing trends are features common to all curves, but they appear shifted to lower temperatures with increasing $\mathrm{Mn}$ contents.
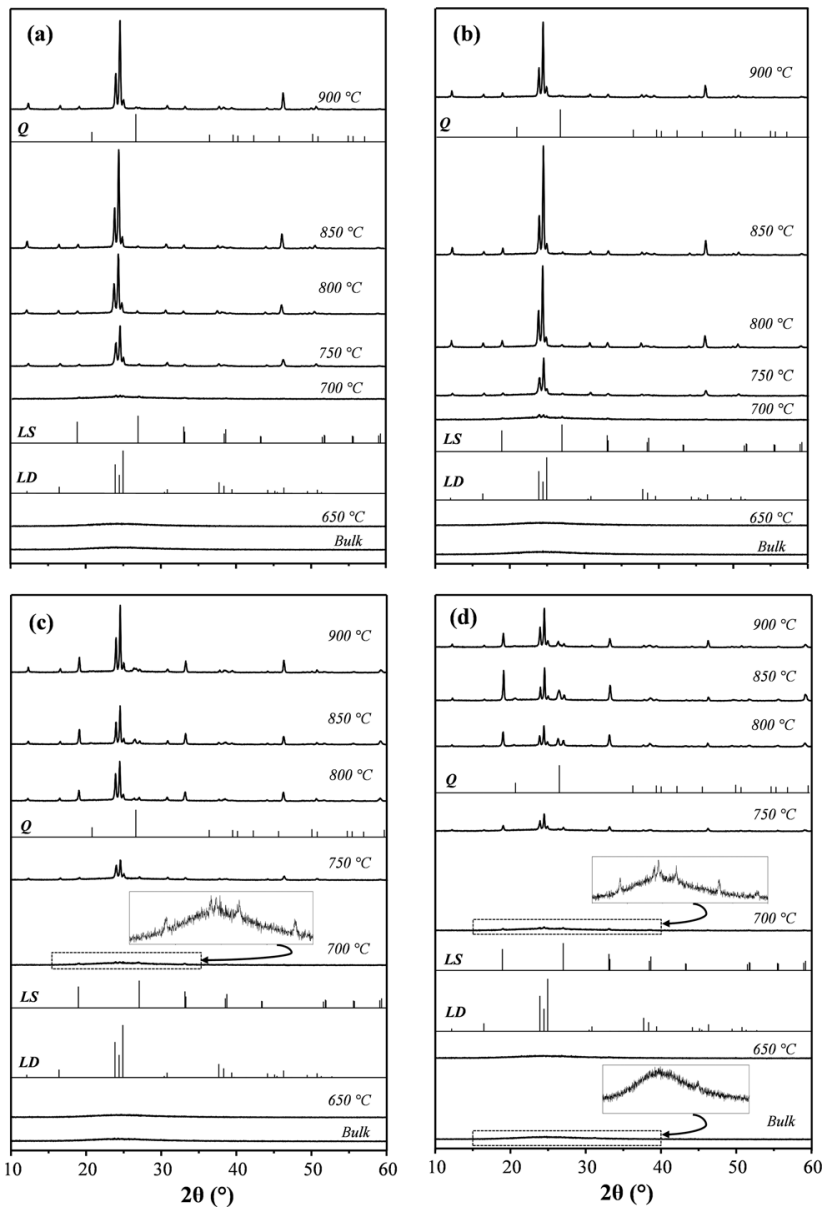

Fig. 8 X-ray diffractograms of bulk glasses (a) GMn0.0, (b) GMnO.5, (c) GMn1.0 and (d) GMn2.0 heat treated at various temperatures for $1 \mathrm{~h}$. LD: lithium disilicate $\left(\mathrm{Li}_{2} \mathrm{Si}_{2} \mathrm{O}_{5}, \mathrm{ICDD}\right.$ card 01-070-4856); LS: lithium metasilicate ( $\mathrm{Li}_{2} \mathrm{SiO}_{3}, \mathrm{ICDD}$ card 01-049-0803); Q: quartz $\left(\mathrm{SiO}_{2}, \mathrm{ICDD}\right.$ card 01-077-1060) [scale bar for (a), (b), (c) \& (d) is 89000 cps].

\section{Discussion}

\subsection{Glass structure}

The heat treatment caused a reduction of $\mathrm{Mn}$ from $\mathrm{Mn}^{4+}$ to lower oxidation states and the release of oxygen, processes that can be described by the following equations:

$$
\begin{aligned}
& \mathrm{MnO}_{2}=\mathrm{Mn}_{2} \mathrm{O}_{3}+1 / 2 \mathrm{O}_{2}(\mathrm{~g}) \\
& \mathrm{Mn}_{2} \mathrm{O}_{3}=2 \mathrm{MnO}+1 / 2 \mathrm{O}_{2}(\mathrm{~g})
\end{aligned}
$$

The evolution of oxygen during glass preparation was responsible for the observed severe bubbling of the melts with increasing Mn contents. Whenever, added to silicate glass systems, Mn tends to exist either in $3+$ or $2+$ oxidation state; higher oxidation states such as $4+$ and $7+$ are possible but very unlikely ${ }^{35,45}$ This redox equilibrium is common in glass systems doped with transition elements, ${ }^{6}$ and several studies ${ }^{6,46,47}$ proved that the redox ratio depends on glass optical basicity $(\Lambda)$ when other parameters are maintained constant. In the present study, the calculated optical basicity $\left(\Lambda_{\text {cal }}\right)$ (Table 2$)$ for the 


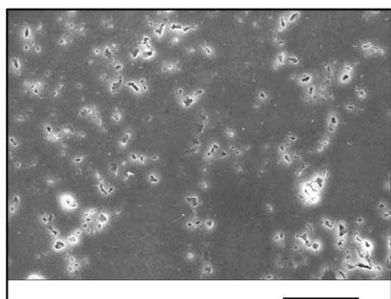

(a) GMn0.0,800 ${ }^{\circ} \mathrm{C} \overline{25 \mu \mathrm{m}}$

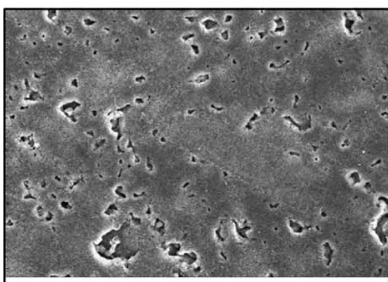

(d) GMn1.0, $800{ }^{\circ} \mathrm{C} \overline{25 \mu \mathrm{m}}$

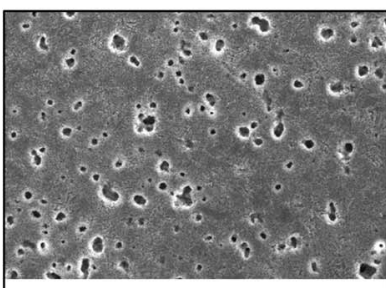

(g) GMn2.0, $800{ }^{\circ} \mathrm{C} \overline{25 \mu \mathrm{m}}$
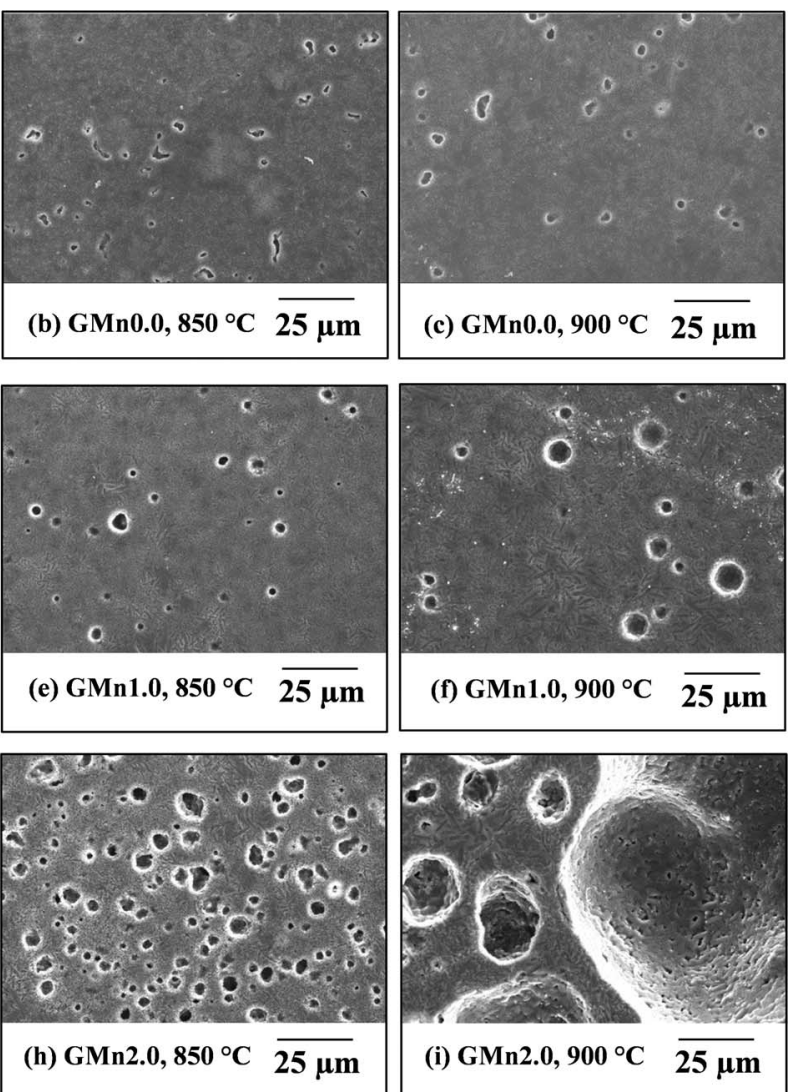

Fig. 9 SEM images showing the effect of sintering temperature and composition on porosity in glass powder compacts heat treated at 800,850 and $900{ }^{\circ} \mathrm{C}$ for $1 \mathrm{~h}$ : (a) to (c) GMn0.0; (d) to (f) GMn1.0; and (g) to (i) GMn2.0.

experimental glasses revealed only slight increments with the composition. These results suggest that similar chemical environment and redox ratio exist in all glass compositions, thus reflecting the constancy of melting conditions used. This hypothesis is supported by a near linear variation at $\lambda=500 \mathrm{~nm}$ of absorbance versus concentration according to Beer-Lambert law (not shown). The redox ratio also depends on several other parameters such as melt temperature, oxygen fugacity $\left(\mathrm{fO}_{2}\right)$ etc. ${ }^{6}$ Silicate glasses prepared by melting in atmospheric oxygen fugacity tend to have Mn majorly in 3+ oxidation state. No evidence of $\mathrm{Mn}^{2+}$ was found by Nelson $e$ al. ${ }^{36}$ in sodium silicate glasses melted in air, since this oxidation state would require reducing conditions during melting. ${ }^{33,35,36,48}$ Optical absorption spectra of present glasses with peak maximum at $\sim 500 \mathrm{~nm}$, a characteristic $\mathrm{Mn}^{3+}$ absorption band for silicate glass systems, further supports the hypothesis that nearly all $\mathrm{Mn}$ in the present experimental glasses exists as $\mathrm{Mn}^{3+}$. In the presence of octahedral ligand field, $\mathrm{Mn}^{3+}$ with $3 \mathrm{~d}^{4}$ electronic configuration experiences Jahn-Teller distortion that causes further splitting of optical absorption bands. ${ }^{35}$ This could result in over masking the weaker absorption bands of $\mathrm{Mn}^{2+}$ if at all present in the system. However, if $\mathrm{Mn}^{3+}$ is present in low spin state, the JahnTeller effect would be weak. In the present glass compositions, for GMn1.0 with high ligand field splitting parameter $\left(\Delta_{\mathrm{o}}\right)$ of $53494 \mathrm{~cm}^{-1}, \mathrm{Mn}^{3+}$ should exist in low spin state and therefore have weak Jahn-Teller effect. Also complex laying on the right side of the vertical line in Tanabe-Sugano diagram of $\mathrm{d}^{4}$, gives rise to spin forbidden states. Anyway, further experiments like EPR spectroscopy and chemical titrations needs to be done to positively confirm the negligible presence of $\mathrm{Mn}^{2+}$ in the system.

Now that we have hypothesized with reasonable assumption that $\mathrm{Mn}$ is present in the glass majorly as $\mathrm{Mn}^{3+}$, it is important to understand its role in the glass network. According to Nelson et al., ${ }^{49}$ transition metal ions when dissolved in glass systems exist as one of the following species in the glass network structure: (1) as individual molecular entities, (2) as quasimolecular complexes, (3) as network modifiers and (4) as network formers. When existing as individual molecular entities, they play no role in the network connectivity of the system. As quasi-molecular complexes, these ions are coordinated with non-bridging oxygens and play some role in the network locally. The difference between quasi molecular complex and network modifiers is basically the type of bonding they form, varying from predominantly covalent to ionic, respectively. With this in mind, we will try identifying the role played by $\mathrm{Mn}$ in the network of our glasses.

The increase in chemical shifts with the added amounts of Mn observed in the ${ }^{29} \mathrm{Si}$ MAS-NMR spectra (Fig. 4a) suggests a network depolymerisation trend and a network modifier role for Mn. But the overall picture should be a bit more complex, considering that $\mathrm{MnO}_{2}$ was added at the expenses of $\mathrm{SiO}_{2}$, 

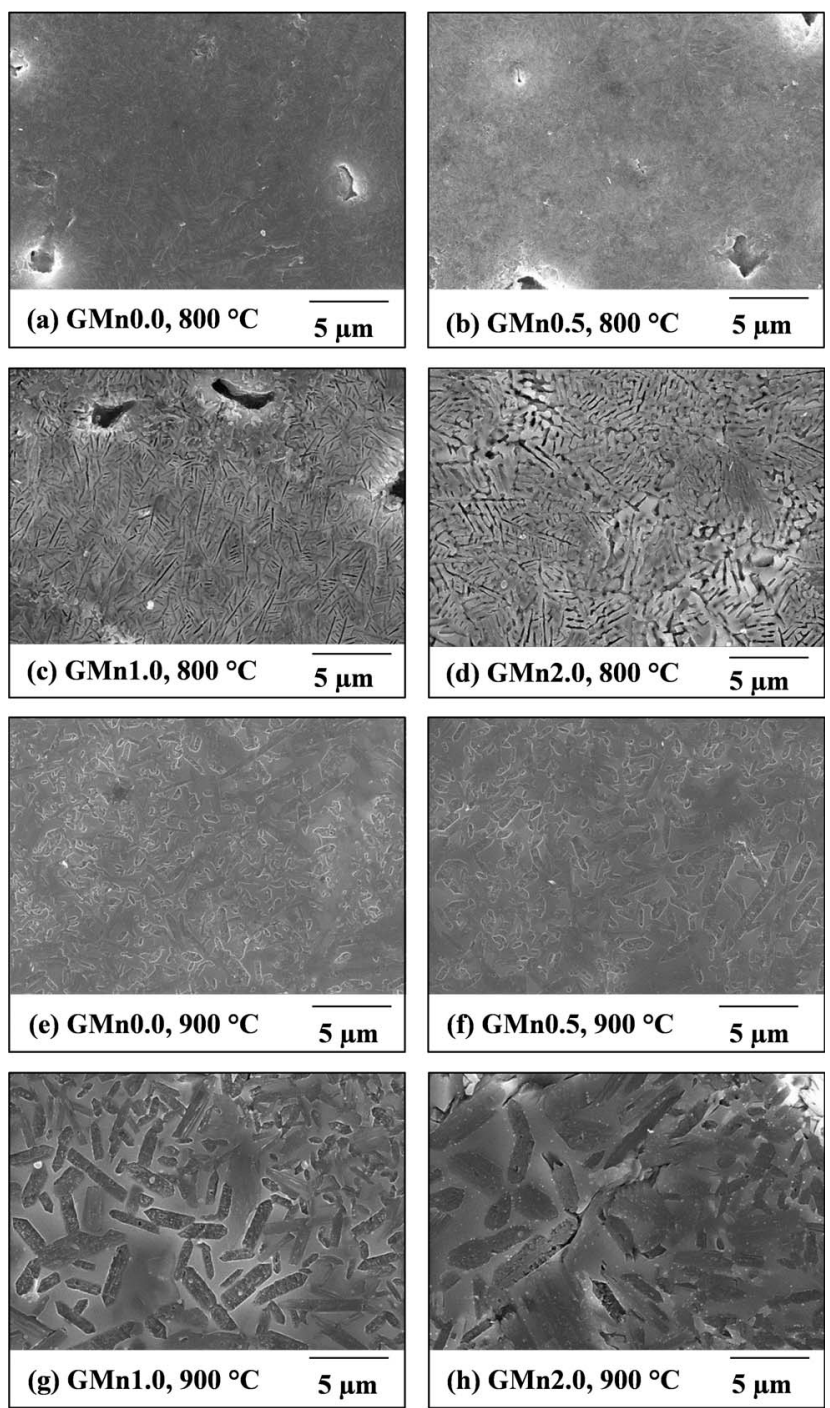

Fig. 10 SEM images showing evolution microstructure of glass powder compacts sintered at: (a) to (d) $800^{\circ} \mathrm{C}$ and (e) to (h) $900^{\circ} \mathrm{C}$.

therefore causing a decrease in the $\mathrm{SiO}_{2} / \mathrm{Li}_{2} \mathrm{O}$ molar ratio (Table 1); which, itself, should result in glass network depolymerization. From the ${ }^{29} \mathrm{Si}$ MAS-NMR spectra it can be inferred that $Q^{3}$ units seem to be the dominant species of $\left[\mathrm{SiO}_{4}\right]^{4-}$ polyhedra. Also with increasing manganese content from 0.5 to $2 \mathrm{~mol} \%$ the overall paramagnetic broadening of the NMR peaks can be noticed due to small additions of paramagnetic ions..$^{50}$ In contrast, no change in the chemical shift can be observed in ${ }^{27} \mathrm{Al}$ MAS-NMR spectra of glasses (Fig. 4b), indicating that network connectivity of $\mathrm{Al}_{2} \mathrm{O}_{3}$ polyhedra was unaffected by $\mathrm{Mn}$ addition. The peak centred at $\sim 52 \mathrm{ppm}$ is attributed to aluminium in tetrahedral coordination, therefore, playing the role of network former.

The FTIR absorption broad band centred at $\sim 1050 \mathrm{~cm}^{-1}$ attributed to various vibrational and stretching modes of $\left[\mathrm{SiO}_{4}\right]^{4-}$ tetrahedra in Fig. 3 tends to exhibit an increasing shoulder near $\sim 950 \mathrm{~cm}^{-1}$ with the addition of $\mathrm{MnO}_{2}$. According to Innocenzi, ${ }^{38}$ this band is associated with the existence of nonbridging oxygens in the glass. This is consistent with NMR
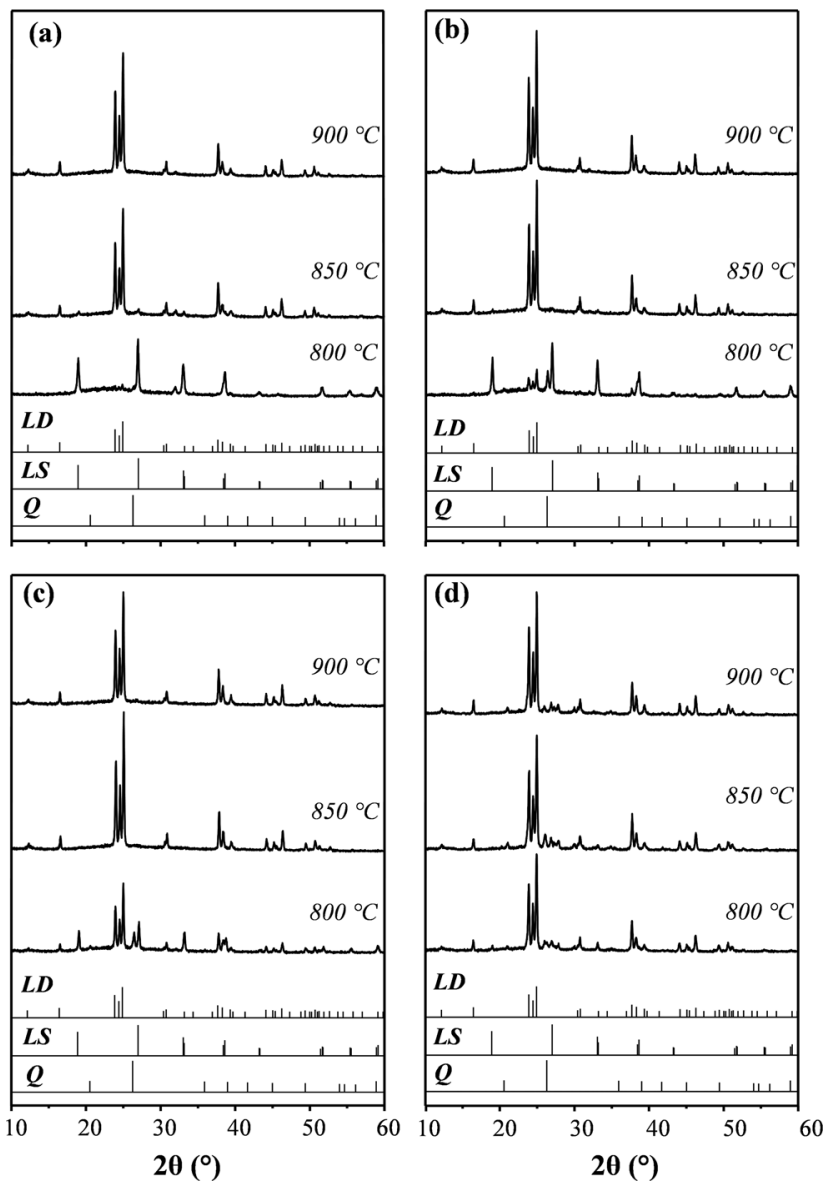

Fig. 11 X-ray diffractograms of sintered glass powder compacts; (a) GMn0.0, (b) GMn0.5, (c) GMn1.0 and (d) GMn2.0 sintered at 800, 850 and $900{ }^{\circ} \mathrm{C}$. LD: lithium disilicate $\left(\mathrm{Li}_{2} \mathrm{Si}_{2} \mathrm{O}_{5}, \mathrm{ICDD}\right.$ card 01-070-4856); LS: lithium metasilicate ( $\mathrm{Li}_{2} \mathrm{SiO}_{3}, \mathrm{ICDD}$ card 01-070-0330); Q: quartz $\left(\mathrm{SiO}_{2}, \mathrm{ICDD}\right.$ card 00-047-1144) [scale bar for (a) (d) is $22400 \mathrm{cps}$ ]

results, confirming that $\mathrm{MnO}_{2}$ addition leads to glass network depolymerisation. On the other hand, the decreasing trend in the band gap energies (Fig. 2) accounts for an increased disorder in the system, also consistent with the formation of non-bridging oxygens that are less prone to tightly bound electrons. ${ }^{51,52}$ So far, all the evidences point out to a possible (but yet non-conclusive) network modifier role of Mn.

The effects of adding network modifiers on molar volume $\left(V_{\mathrm{m}}\right)$ of a glass depend on their ionic radii. ${ }^{53}$ For example, smaller radii alkali earth metals $(\mathrm{Li}, \mathrm{Na})$ that can fit in interstitial positions of a glass would lead to network shrinkage (smaller $V_{\mathrm{m}}$ values); while the addition of $\mathrm{K}, \mathrm{Rb}$ and Cs would lead to network expansion of the same glass. Assuming a network modifier role for $\mathrm{Mn}$ in the present system, an overall decrease in $V_{\mathrm{m}}$ should be expected as ionic radii of $\mathrm{Mn}$ ions $(0.58-0.64 \AA)$ are in the same range as $\mathrm{Li}^{1+}$ ion $(0.59-0.92 \AA) .{ }^{54}$ But Table 2 shows a first decrease of $V_{\mathrm{m}}$ upon adding $0.5 \mathrm{~mol} \%$ Mn (GMn0.5) and a subsequent increase with further Mn additions, with the value for GMn2.0 being greater than that of GMn0.0. This increase in $V_{\mathrm{m}}$ suggests that $\mathrm{Mn}$ is acting more as a network former, thus contradicting the continuous depolymerization trend inferred from NMR and FTIR results. All these 

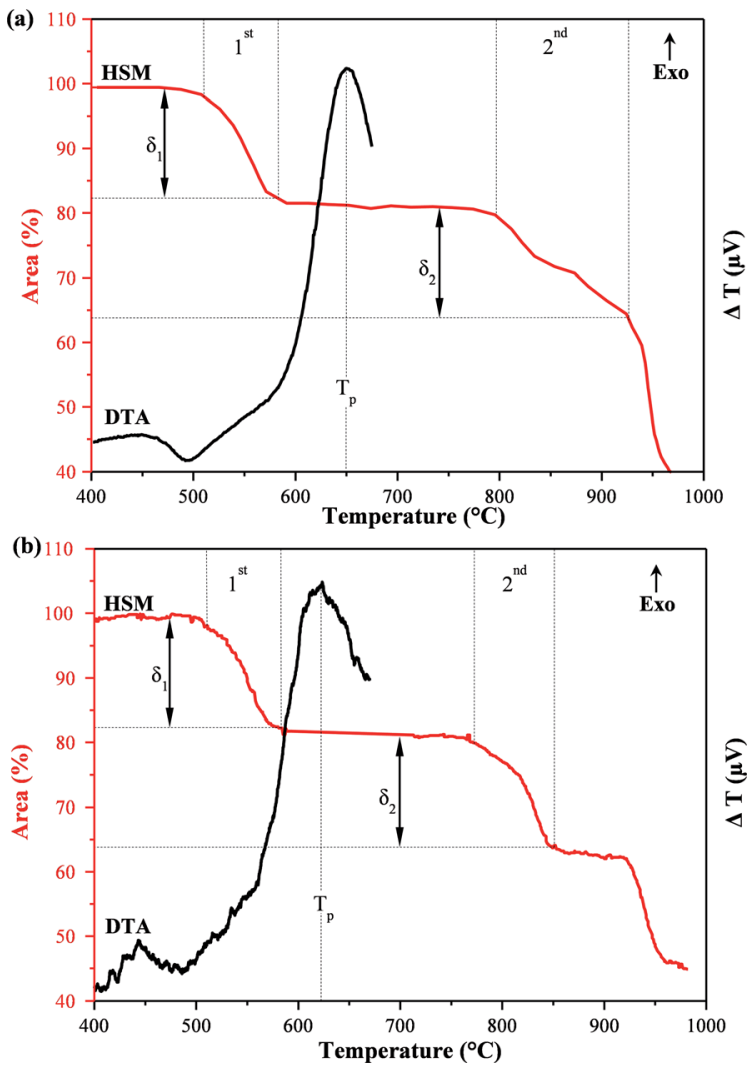

Fig. 12 DTA and HSM curves for glass powder compacts: (a) GMn0.0 and (b) GMn2.0.

Table 3 Characteristic points of crystallization and sintering in glasses

\begin{tabular}{llcc}
\hline & & GMn0.0 & GMn2.0 \\
\hline \multirow{2}{*}{ DTA } & & 490 & 486 \\
& $T_{\mathrm{g}} \pm 2\left({ }^{\circ} \mathrm{C}\right)$ & 571 & 560 \\
& $T_{\mathrm{c}} \pm 2\left({ }^{\circ} \mathrm{C}\right)$ & 648 & 624 \\
& $T_{\mathrm{p}} \pm 2\left({ }^{\circ} \mathrm{C}\right)$ & 510 & 510 \\
& $T_{\mathrm{FS} 1} \pm 5\left({ }^{\circ} \mathrm{C}\right)$ & 583 & 583 \\
& $T_{\mathrm{MS} 1} \pm 5\left({ }^{\circ} \mathrm{C}\right)$ & 18 & 18 \\
$\mathrm{HSM}$ & $\delta_{1}(\%)$ & 794 & 775 \\
& $T_{\mathrm{FS} 2} \pm 5\left({ }^{\circ} \mathrm{C}\right)$ & 928 & 851 \\
& $T_{\mathrm{MS} 2} \pm 5\left({ }^{\circ} \mathrm{C}\right)$ & 19 & 19 \\
& $\delta_{2} \pm 5(\%)$ & 945 & 937 \\
\hline
\end{tabular}

evidences make it difficult assuming either network modifier or network former roles for $\mathrm{Mn}$. It is likely that $\mathrm{Mn}$ forms individual molecular entities or quasi-molecular complexes without interacting much with the glass network.

The $\Delta_{\mathrm{o}}$ and $B$ crystal field parameters drawn from UV-Visible spectroscopy results of GMn1.0 glass can give further hindsight regarding the bonding of this system. If the transition metal acts as network modifier, it is coordinated with non-bridging oxygens by ionic bonds having larger $B$ values due to enhanced electron repulsion among the anions. But being weaker, ionic bonds show smaller $\Delta_{\mathrm{o}}$ values. In the case of covalent bonding, overlapping of the atomic orbitals would result in the formation of molecular orbitals with an expansion of the electron cloud, the
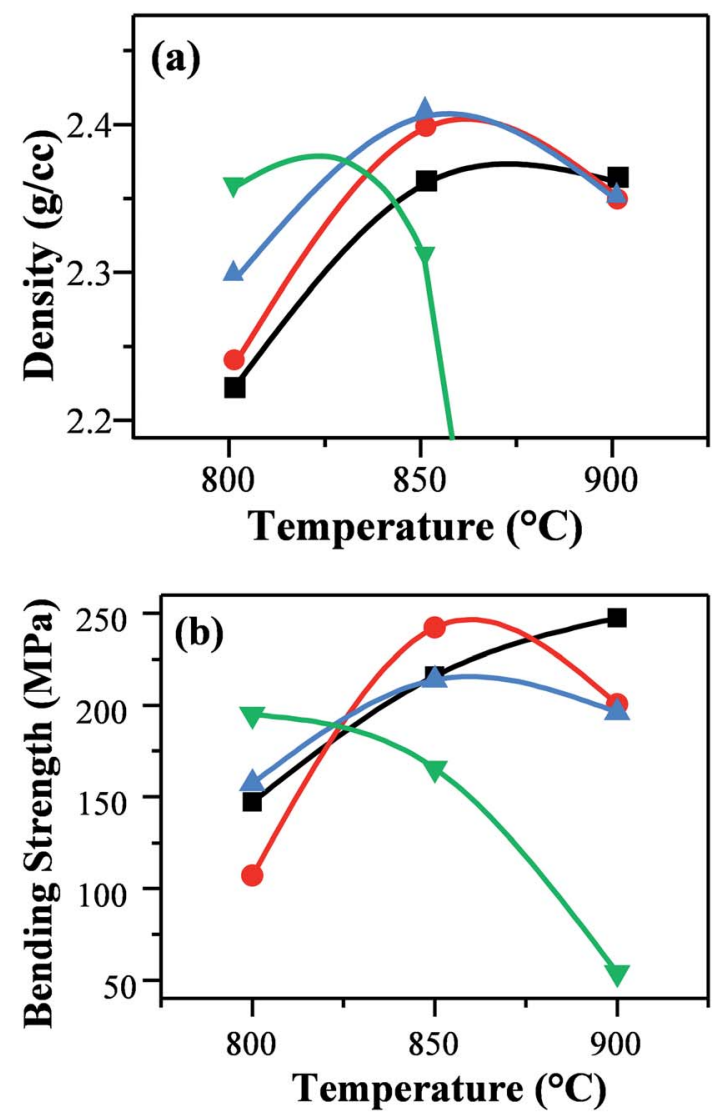

Fig. 13 Some properties of sintered glass powder compacts heat treated at different temperatures; (a) density and (b) bending strength;

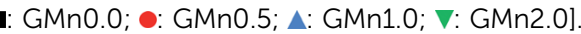

well-known Nephelauxetic effect; as a result they show lower $B$ values. ${ }^{48}$ Being stronger, covalent bonds show larger $\Delta_{\mathrm{o}}$ values. In other words, $B$ and $\Delta_{\mathrm{o}}$ values should decrease and increase, respectively, if transition metal ions act as network formers and form covalent bonds. In the present case larger values of both $B$ and $\Delta_{\mathrm{o}}$ can be observed. This supports the hypothesis that $\mathrm{Mn}$ present in network interstitials is coordinated with oxygen atoms forming almost independent structural units. Mn bonded to oxygen in octahedral coordination might account for the high $\Delta_{\mathrm{o}}$ values, while the isolation of the structural units could help explaining the high $B$ values. Upon studying the effects of small additions of $\mathrm{Mn}$ into sodium silicate glasses, Mortuza et al. ${ }^{\mathbf{5 0}}$ arrived to a similar conclusion, suggesting that $\mathrm{Mn}$ is not chemically bonded to the glass network.

The replacement of silica by $\mathrm{MnO}_{2}$ and the consequent decrease of $\mathrm{SiO}_{2} / \mathrm{Li}_{2} \mathrm{O}$ ratio are expected to cause depolymerization of the glass network as seen from MAS-NMR and FTIR spectra. However, the network contraction might be hindered by Mn structural units present in the interstitials that tend to cause network expansion. The relatively constant $T_{\mathrm{g}}$ values (458-467 ${ }^{\circ} \mathrm{C}$ ) (Table 2) also support this interpretation, otherwise a more accentuated reduction in $T_{\mathrm{g}}$ should have been observed.

According to the $\mathrm{Li}_{2} \mathrm{O}-\mathrm{SiO}_{2}$ phase diagram, for $\mathrm{SiO}_{2} / \mathrm{Li}_{2} \mathrm{O}$ ratios less than 5.5 the droplets observed in the micrographs of annealed glasses (Fig. 6) are $\mathrm{SiO}_{2}$-rich dispersed in the $\mathrm{Li}_{2} \mathrm{O}$-rich 
matrix. ${ }^{52,55}$ Moreover, an overall reduction in phase segregation can be noticed from the SEM images. This suggests that the formation of Mn structural units increased the glass viscosity and, as a consequence, reduced its tendency to immiscibility. For a better understanding of these structural units, further experiments, including molecular dynamic simulations, will be required to shed light on its chemical nature and structure.

\subsection{Crystallization in bulk glasses}

Heat treating the glasses at various temperatures $\left(650-900{ }^{\circ} \mathrm{C}\right)$ resulted in bulk and surface crystallization, as seen in the optical micrographs of GMn0.0 and GMn0.5 heat treated at $700{ }^{\circ} \mathrm{C}$ (Fig. 7a and b). But the number of crystals in the bulk tends to decrease with incremental additions of Mn due to a less favourable homogenous nucleation in the glass. Using classical and adiabatic nucleation theories, Zanotto ${ }^{56,57}$ proved that glasses tend to nucleate homogenously when $T_{\mathrm{gr}}$ is less than $\sim 0.58-0.60$. The $T_{\mathrm{gr}}$ values reported in Table 2 shows are within or even below this range. Therefore, adding $\mathrm{Mn}$ into the system reduces the overall tendency for homogenous nucleation and enhances surface crystallization. Several studies ${ }^{57}$ proved that liquid-in-liquid phase segregation in glass promotes nucleation. Phase segregated regions with a composition similar to that of crystals would reduce the kinetic barrier for nucleation. This explains the decreasing number of crystalline clusters in bulk (Fig. 7) or even its absence in the case of GMn2.0 glass. The increase in the $T_{\mathrm{gr}}$ is attributed to an increase in glass viscosity.

Mn-rich structural units do not appear to have much effect on glass viscosity at higher temperatures as deduced from the decreasing $T_{\mathrm{p}}$ values (Fig. 5). This would result in an overall decrease in the activation energy for crystallization with increasing Mn contents. But the concomitant less bulk nucleation extent in glasses resulted in low crystalline content (Fig. 10). The overall depolymerization trend of glass network seems to predominate at higher temperatures causing the crystals to growth. But viscosity measurements and crystallization kinetics studies would be required to better understand these phenomena in the present glasses.

\subsection{Sintered glass powder compacts}

From the SEM microstructures of glass powder compacts sintered at various temperatures shown in Fig. 9, it can be seen that adding Mn (GMn0.0, GMn0.5 and GMn1.0) enhanced densification at lower temperatures $\left(800-850{ }^{\circ} \mathrm{C}\right)$. But further increasing the Mn content (GMn2.0) and sintering temperature $\left(900{ }^{\circ} \mathrm{C}\right)$ tended to reduce density. Only the GMn0.0 sample shows proper densification at $900{ }^{\circ} \mathrm{C}$. There was a clear trend for the formation of pores of increasing size with increasing $\mathrm{Mn}$ contents and sintering temperatures. This can be explained by gas release inside a glassy phase according to eqn (5 and 6) at a higher temperature during sintering and crystallization.

The features of crystals formed upon sintering the glass powder compacts at $800{ }^{\circ} \mathrm{C}$ and $900{ }^{\circ} \mathrm{C}$ are shown in the higher magnification SEM images of Fig. 10. At both temperatures the size of crystals noticeably increased with increasing $\mathrm{Mn}$ contents due to the lowering of glass viscosity and of the activation energy for crystallization. This decrease in activation energy for crystallization is consistent with the reduction in the $T_{\mathrm{p}}$ (Fig. 5 and Table 2) and with the XRD spectra displayed in Fig. 11, favouring the crystallization process at lower temperatures. Upon sintering at $800{ }^{\circ} \mathrm{C}$, LS was the main crystalline phase obtained from GMn0.0, while the formation of LD was favoured from Mn-containing compositions.

The HSM and DTA curves of GMn0.0 and GMn2.0 glass powders compacts presented in Fig. 12 and the corresponding results reported in Table 3 shed further light on the sequence of thermal events. Until the first shrinkage $\left(T_{\mathrm{FS} 1}\right)$ and maximum shrinkage $\left(T_{\mathrm{MS} 1}\right)$ both GMn0.0 and GMn2.0 curves followed similar HSM profiles and reached the same $T_{\mathrm{FS} 1}$ and $T_{\mathrm{MS} 1}$ values. The formation of necks among the glass particles, especially among the smaller ones starts at $T_{\mathrm{FS} 1}$ (ref. 60) and gradually extends to the coarser ones, making the compact to shrink. But the meanwhile occurrence of devitrification manifested by the exothermic DTA peak tends to hamper further densification. These opposite influences lead to the first maximum shrinkage. The comparison of HSM and DTA curves displayed in Fig. 12 shows that nucleation/crystallization processes started at lower temperatures in the GMn2.0 sample, likely due to its lower activation energy. Moreover, $T_{\mathrm{p}}$ values are $<700{ }^{\circ} \mathrm{C}$, the temperature at which the first XRD signs of crystallization appeared for bulk glasses (Fig. 12). This suggests that heterogeneous nucleation is taking place at the surface of glass particles.

The balance between densification and crystallization processes leads to the observed shrinkage plateau. With temperature increasing the remaining glassy phase softens and stimulates surface and bulk diffusion and a second shrinkage $\left(T_{\mathrm{FS} 2}\right)$ step starts and continues while the driving forces for densification will predominate over the crystallization and phase transformation. The crystallization process and the second maximum shrinkage $\left(T_{\mathrm{MS} 2}\right)$ occur earlier for GMn2.0 in comparison to GMn0.0. Heat treating GMn2.0 above $T_{\mathrm{MS} 2}$ resulted in over firing effects expressed by swelling/foaming due to the release of oxygen inside a partial melted glass. This foaming tendency with increasing $\mathrm{Mn}$ contents is clearly illustrated by the increasing porosity (Fig. 8). It is also consistent with the evolution of density and bending strength values of sintered glass powder compacts presented in Fig. 13, especially by the accentuated decreases observed for GMn2.0 at higher temperatures. General increasing trends up to maximum values of these two properties, followed by decreasing tendencies are observed for the other compositions, but the curves appear shifted to lower temperatures as Mn content increases. In the case of GMn0.0, there is a continuous increase in the bending strength with sintering temperature. For GMn0.5 and GMn1.0 the maximum bending strength is reached at $850{ }^{\circ} \mathrm{C}$ and after that, at $900{ }^{\circ} \mathrm{C}$ the bending strength values decline. In the case of GMn2.0, there is a continuous decrease in the bending strength values.

\section{Conclusions}

Small additions of $\mathrm{MnO}_{2}$ to the experimental glass imparted huge changes on crystallization of bulk/particulate glasses and 
on sintering behaviour of glass powder compacts. The following conclusions could be drawn from the above discussion:

1. Well-known redox equilibrium of $\mathrm{Mn}^{2+} / \mathrm{Mn}^{3+}$ with predominance of $\mathrm{Mn}^{3+}$ was established in Mn-doped glasses giving rise to purple colour.

2. MAS-NMR and FTIR spectroscopy suggest a network modifier role for $\mathrm{Mn}$; whereas relatively constant $T_{\mathrm{g}}$ values (458$467^{\circ} \mathrm{C}$ ), increasing $V_{\mathrm{m}}$ and decreasing phase separation suggest network former role.

3. The involvement of $\mathrm{Mn}$ in the formation of individual molecular units in the interstitials of the depolymerized glass network explanation is the proposed conciliating view about the role of $\mathrm{Mn}$ in glasses. Large crystal field parameters $\left(\Delta_{\mathrm{o}}, B\right)$ and the lowering trend for glass-in-glass phase separation both agree with this hypothesis.

4. The lowering trend for glass-in-glass phase separation in turn lead to reduced bulk nucleation. Therefore Mn increased the kinetic barrier for nucleation near $T_{\mathrm{g}}$.

5. Oppositely, the peak crystallization temperature $\left(T_{\mathrm{p}}\right)$ from DTA showed a decreasing trend pointing out to lower activation energy for crystallization from a less polymerized glass network.

6. Sintering and crystallization occurred at lower temperatures in Mn-doped glass powder compacts conferring higher strength at low sintering temperatures. But the occurrence of foaming in Mn-doped samples at higher temperatures drastically reduced density and mechanical strength.

\section{Acknowledgements}

This study was financially supported by CICECO, University of Aveiro, Portugal. Hugo R. Fernandes is grateful for the PostDoctoral Grant (SFRH/BPD/86275/2012) from the Fundação para a Ciência e a Tecnologia (FCT), Portugal.

\section{References}

1 A. H. Reidies, Ullmann's Encycl. Ind. Chem., 2002, pp. 495542.

$2 \mathrm{H}$. Bach and D. Krause, Low thermal expansion glass ceramics, Springer, Berlin, 1995.

3 R. Van Noort, Introduction to Dental Materials, Mosby, Sheffield, 2002.

4 W. B. White and D. S. Knight, Mater. Res. Soc. Symp. Proc., 1986, 61, 283-293.

5 W. H. Turner and J. E. Turner, J. Am. Ceram. Soc., 1970, 53, 329-335.

6 H. Schreiber, J. Non-Cryst. Solids, 1986, 84, 129-141.

7 H. D. Schreiber, B. K. Kochanowski, C. W. Schreiber, A. B. Morgan, M. T. Coolbaugh and T. G. Dunlap, J. NonCryst. Solids, 1994, 177, 340-346.

8 A. V. Sarukhanishvili, Y. Shashek, E. V. Shapanidze and I. A. Sarukhanishvili, Steklo Keram., 1992, 4, 4-5.

9 E. A. Rode, Oxygen Compounds of Manganese [in Russian], Izvestiya Akademii Nauk SSSR, Moscow, 1952.

10 R. Bufala, Bol. Soc. Esp. Ceram. Vidrio, 1971, 10, 247-260.

11 I. Bratu, I. Ardelean, A. Barbu, V. Mih, D. Maniu and G. Botezan, J. Mol. Struct., 1999, 482-483, 689-692.
12 L. E. Orgel, J. Chem. Phys., 1955, 23, 1824-1826.

13 S. Parke and R. S. Webb, Phys. Chem. Glasses, 1972, 13, 157160.

14 D. Simkin, K. Oyama-Gannon, P. Menassa and P. Taylor, J. Lumin., 1981, 24-25, 107-110.

15 N. K. Mohan, M. R. Reddy, C. K. Jayasankar and N. Veeraiah, J. Alloys Compd., 2008, 458, 66-76.

16 M. S. Reddy, G. Murali Krishna and N. Veeraiah, J. Phys. Chem. Solids, 2006, 67, 789-795.

17 T. Pradell, G. Molina, J. Molera, J. Pla and a. Labrador, Appl. Phys. A, 2012, 111, 121-127.

18 M. C. Caggiani and P. Colomban, J. Raman Spectrosc., 2011, 42, 839-843.

19 B. Karasu and S. Turan, J. Eur. Ceram. Soc., 2002, 22, 14471455.

20 N. Srisittipokakun, K. Kirdsiri, J. Kaewkhaoi, C. Kedkaewdan and P. Limsuwan, Procedia Eng., 2011, 8, 261-265.

21 T. W. Cheng, M. Z. Huang, C. C. Tzeng, K. B. Cheng and T. H. Ueng, Chemosphere, 2007, 68, 1937-1945.

22 Y. Sun, Z. Wang, J. Tian and X. Cao, Zhonghua Kouqiang Yixue Zazhi, 2003, 38, 137-139.

23 L. D. Bogomolova, G. E. G. Grechko, N. A. Krasil'nikova and V. V. Sakharov, J. Non-Cryst. Solids, 1985, 69, 299-307.

24 A. Van Die, A. C. H. I. Leenaers, G. Blasse and W. F. Van Der Weg, J. Non-Cryst. Solids, 1988, 99, 32-44.

25 A. S. Rao, B. Sreedhar, J. L. Rao and S. J. V. Lakshman, J. NonCryst. Solids, 1992, 144, 169-174.

26 G. Srinivasarao and N. Veeraiah, J. Alloys Compd., 2001, 327, 52-65.

27 I. Ardelean, G. Ilonca, V. Simin, O. Cozar and V. Ioncu, Solid State Commun., 1996, 98, 651-653.

28 X.-R. Wang, Y. Zhang, T. Ma, C.-S. Deng and X.-M. Dai, Ceram. Int., 2012, 38, S57-S60.

29 B. Vaidhyanathan, C. P. Kumar, J. L. Rao and K. J. Rao, Phys. Chem. Glasses, 1998, 59, 121-128.

30 R. P. Sreekanth Chakradhar, K. P. Ramesh, J. L. Rao and J. Ramakrishna, J. Phys. Chem. Solids, 2003, 64, 641-650.

31 D. K. Durga and N. Veeraiah, J. Phys. Chem. Solids, 2003, 64, 133-146.

32 J. M. Giehl, a. R. Miranda, W. M. Pontuschka, M. Navarro and Z. M. Costa, J. Supercond. Novel Magn., 2012, 26, 22952298.

33 A. Winterstein and H. Akamatsu, Opt. Mater. Express, 2013, 3, 184-193.

34 A. Terczyńska-Madej, K. Cholewa-Kowalska and M. Łączka, Opt. Mater., 2011, 33, 1984-1988.

35 I. Konidakis and C. Varsamis, J. Phys. Chem. C, 2010, 114, 9125-9138.

36 C. Nelson and W. White, Geochim. Cosmochim. Acta, 1980, 44, 887-893.

37 A. Paul, Chemistry of Glasses, Chapman and Hall, 2nd edn, 1990.

38 P. Innocenzi, J. Non-Cryst. Solids, 2003, 316, 309-319.

39 B. H. W. S. De Jong, C. M. Schramm and V. E. Parziale, J. Am. Chem. Soc., 1984, 106, 4396-4402.

$40 \mathrm{H}$. R. Fernandes, D. U. Tulyaganov, A. Goel and J. M. F. Ferreira, J. Therm. Anal. Calorim., 2011, 103, 827-834. 
41 H. A. Abo-Mosallam, R. G. Hill, N. Karpukhina and R. V. Law, J. Mater. Chem., 2010, 20, 790-797.

42 J. F. Stebbins, S. Kroeker, S. K. Lee and T. J. Kiczenski, J. NonCryst. Solids, 2000, 275, 1-6.

43 A. A. Cabral Jr, C. Fredericci and E. D. Zanotto, J. Non-Cryst. Solids, 1997, 219, 182-186.

44 J. a. Duffy, J. Chem. Educ., 1996, 73, 1138.

45 A. Terczynska-Madej, K. Cholewa-Kowalska and M. Laczka, Opt. Mater., 2010, 32, 1456-1462.

46 P. Claes and E. Decelle, J. Non-Cryst. Solids, 2001, 288, 37-45.

47 W. Thiemsorn, K. Keowkamnerd, S. Phanichphant, P. Suwannathada and H. Hessenkemper, Glass Phys. Chem., 2011, 34, 19-29.

48 J. Duffy, M. Ingram and S. Fong, Phys. Chem. Chem. Phys., 2000, 2, 1829-1833.

49 C. Nelson, Mater. Res. Bull., 1983, 18, 959-966.

50 M. G. Mortuza, R. Dupree and D. Holland, J. Mater. Sci., 2000, 35, 2829-2832.
51 A. Higazy, A. Hussein and M. Awaida, J. Mater. Sci. Lett., 1989, 24, 2203-2208.

52 W. Vogel, Glass Chemistry, Springer, Berlin, 1994.

$53 \mathrm{~J}$. Shelby, Introduction to glass science and technology, The Royal Society of Chemistry, Thomas Graham House, Science Park, Milton Road, Cambridge CB4 OWF, UK, 2nd edn, 2005.

54 R. Shannon, Acta Crystallogr., Sect. A: Cryst. Phys., Diffr., Theor. Gen. Crystallogr., 1976, 32, 751-767.

55 C. B. Carter and M. G. Norton, Ceramic materials - science and engineering, Springer, New York, 2007.

56 E. Zanotto, J. Non-Cryst. Solids, 1987, 89, 361-370.

57 E. D. Zanotto, Int. J. Appl. Glass Sci., 2013, 4, 105-116.

58 E. D. Zanotto, P. F. James and A. F. Craievich, J. Mater. Sci., 1986, 21, 3050-3064.

59 A. Ramsden and P. James, J. Mater. Sci., 1984, 19, 1406-1419.

60 H. R. Fernandes, D. U. Tulyaganov, M. J. Pascual, V. V. Kharton, A. a. Yaremchenko and J. M. F. Ferreira, J. Eur. Ceram. Soc., 2012, 32, 2283-2292. 